\title{
Hormonal Assay in Infertility Cases of Women
}

\author{
M. Indira ${ }^{1}$, Ch. Sudhakar babu ${ }^{2}$ \\ ${ }^{1}$ Assistant Professor, Dept. of Biochemistry, S.V. Medical College, Tirupathi, A.P, India, NTRUHS \\ ${ }^{2}$ Assistant Professor, Dept. of Anatomy, S.V. Medical College, Tirupathi, A.P, India, NTRUHS
}

\begin{abstract}
The present study was undertaken to evaluate the endocrinal causes of infertility in women. Infertility affects 10-15\% Of couples of reproductive age groups and female factor is responsible for $40-50 \%$ of cases, most common causes of female infertility are ovulatory disfunction and thyroid hormone, and estrogen ,progestiron, and serum Prolactin dysfunction . Estimation of FSH,LH, and thyroid hormones useful in diagnosis the type of ovulatory disfunction and useful in deciding the mode of treatment. The present study has been undertaken to evaluate hormone levels $(F H S, L H$,$) in ovulatory disfunction cases of female infertility after$ elimination of PCOD the fertility of female reproductive system is maintained by prevaling hormonal mainly which is delicately balanced by Hypothalamic ,Pituitary, Thyroid, adrenal and gonadal axis .The problem of infertility are faced from the time of evaluation of man will probably remain with as forever. little is added every year to the present understanding and more remains unknown Infertility affects 10-15\% of couples of reproductive age groups. Male factor in 25-40 \% female factor in 40-55\% .male and female in 10\%, unexplained in $10 \%$ cases are responsible for infertility .ovulatory dysfunction is responsible for upto $40 \%$ of female cases and for 20-25\% of total infertility cases
\end{abstract}

Key words: Female infertility, FHS, LH, TSH, T3,T4, Hypo\& Hyper Gonadotrophic anovulation

\section{Introduction}

Human beings can not help thinking alone ,may longing for what they don't have ,particularly when every one round them has it in abundance .procreation is a very basic biological urge. It is hence logical that the infertile couple be offered every scientific aid available to them to attain freedom from their sense of void, so that they may have the pleasure and fulfillment of bearing their own pregnancy. Endocrinological abnormalities are frequently encuontered and most effectivly treated causes of infertility. ${ }^{1}$ We must in particular recognize the right of women to bear her own child if she so desires. Infertility is defined as one year of unprotected coitus without conception this condition may be further classified as primary infertility in which a prior pregnancy has occurred .Infertility affects approximately 10-15\% reproductive age couples in U.S.A - $17 \%, 26 \%$ IN U.K ,21\% in canada ,13\% IN DENMARK ,14\% IN SCOTLAND ,5.4\% IN ISRAELI ,In INDIA incidence varies from $5-15 \%$ in south INDIA $8-10 \%$ Infertility is a common accompaniment of disorders of thyroid function both the hypothyroidism as well as hyperthyroidism are associated with variety of changes in reproductive function including of delayed onset of puberty, an ovulation and abnormally high fetal wastage .subtle changes in thyroid function may have permissive role in the production of absolute \&relative infertility in some individuals. ${ }^{2}$ Both primary and secondary types of infertility generally share common causes. The incidence of infertility has been increasing in the last decade. Awareness of infertility has increased as couples have become more willing to seek medical advice .Infertility problems often arise as a result of hormonal dysfunction of hypothalamo-pituitary gonadal axis. ${ }^{3}$ Measurement of peptide and steroid hormones in the serum are therefore essential aspects of the evaluation of infertility.

\section{Materials And Methods}

The study included a total no of 63 cases of infertility cases of women and the present study was carried out in the Dept of obstetrics and Gynaecology of maternity hospital of SVMC and collaboration with Dept of Endocrinology, SVIMS Tirupati .The couples with either primary or secondary infertility were selected successively and evaluated for male factor, non- endocrinological causes of infertility and then subjected to endocrinological evaluation

Controls :Controls were selected on the basis of normal menstrual history, no systemic illness ,no contraceptive history and are fertile, and in good health ,63 an- ovulatory patients were studied against 30 controls of 20 to 30 age group.

Collection of samples:Whole blood was collected on day 7 of menstrual cycle from controls. 3 samples of whole blood was collected from patients at an interval of 20 minutes and pooled. Clear serum without hemolysis is separated into clean bottles and labeled and measured for hormonal assay. Depending upon the values obtained the patients are divided into 3 categories ${ }^{10}$ 


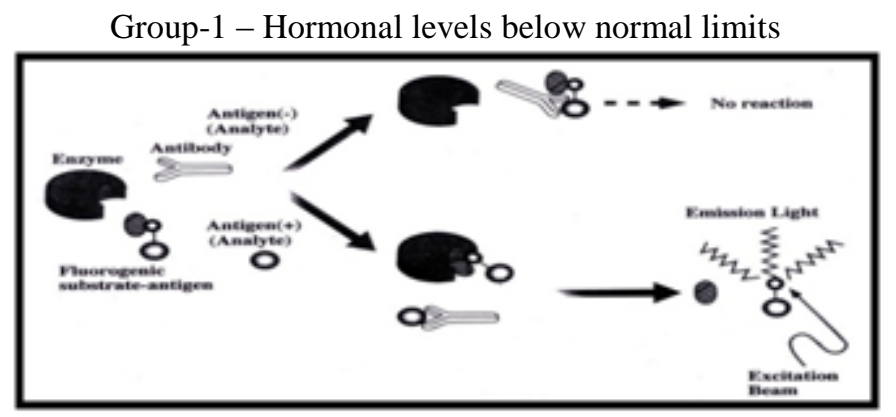

Group-2 -Hormonal levels within normal limits Group-3 -Hormonal levels above normal limits Estimation:

Estimation of lutropin, Follitropin, Thyrotrpin,T3,T4 levels by

Fluoro-Immuno assay method (FIA) This methods is most sensitive than the radio immuno assay and ELISA. We can detect even less than $1 \mathrm{ng} / \mathrm{ml}$ of analyte and we can also avoid risk of radiation by this method.

\section{Enzyme linked fluorescent Assay}

Principle

Enzyme linked fluorescent Assay are identical to other EIAS except that they use fluorescent Substrates. In the EIFA a florophore is generated by an enzyme reaction.

The substrate $\beta$-galactosyl umbelliferone is conjugated with the antigen (analyte) and forms non fluorescent substrate. The substrate can be cleaved by an enzyme $\beta$-galactosidase to form a fluorescent product. However when the substrate - antigen conjugate is allowed to react with specified antibody to the antigen, there is no cleavage of the substrate complex with the $\beta$-galactosidase enzyme. In this assay the concentration of the antigen (analyte) is directly proportional to the fluorescent intensity measured. Flurophor used-4methylumbelliferone (4-MU)Instrument calibration is provided using a standard calibration solution in a VIDAS strip prepared by bioMerieux. These calibration strips are checked by QC/QA and values are assigned to the strip [approximately a 3,200 RFU reading with an $8,000 \mathrm{nM}$ solution of solution of 4-methylumbelliferone (4MU) in a buffer].

Flurophor used-4-methylumbelliferone (4-MU): Instrument calibration is provided using a standard calibration solution in a VIDAS strip prepared by bioMerieux. These calibration strips are checked by QC/QA and values are assigned to the strip [approximately a 3,200 RFU reading with an $8,000 \mathrm{nM}$ solution of solution of 4-methylumbelliferone (4-MU) in a buffer].

\section{Methods} methods:

The FIA uses several different methods to calculate results. There are three basic categories of analysis

Patient to standard: A comparison of the Relative Fluorescence Value (RFV) of the test sample to that of a standard. This method is used in single reagent strip qualitative and most semi-quantitative assays.

Patient to reference: A comparison of the RFV of the test sample to that of a reference blank This method IS used In dual reagent strip qualitative assays

Curve fitting equations: The RFV of a test sample is mathematically placed on a calibration curve. This method is used for all quantitative and some semi-quantitative assays.

If the test value is:

the result is:

$>$ or $=$ high threshold

$<$ high threshold and

positive

equivocal

$\geq$ low threshold

$<$ low threshold

equivocal

negative

\section{Expected Values in FIA method}
1. T3
$=0.92-2.33 \mathrm{mIU} / \mathrm{ml}$
2. $\mathrm{T} 4$
$=6.0-12 \mathrm{mIU} / \mathrm{ml}$

3. $\mathrm{TSH}=$

Euthyroid 0.25-5 mIU/ml Hyperthyroid < $0.15 \mathrm{mIU} / \mathrm{ml}$ Hypothyroid $>7 \mathrm{mIU} / \mathrm{ml}$

4. $\mathrm{FSH}=$

Ovulatory peak 6.3-24.0 mIU/ml Follicular phase First half - 3.9-12.0 mIU/ml

Second half - 2.92-9.0 mIU/m Luteal phase - 1.5-7.0 mIU/ml Menopause - 17.0-95.0

$\mathrm{mIU} / \mathrm{ml}$ 5. LH= Ovulatory peak 9.62-800 mIU/ml Follicular phase First half - (D1-D3) 5-8 
Second half - (D8-D12) 2-8 mIU/m Luteal phase - (D13-D15) 0.2-6.5 mIU/mlMenopause - 8.0$33.0 \mathrm{mIU} / \mathrm{ml}$

RESULTS: The dysfunctioning of the Lutropin (LH), follicular stimulating hormone (FSH) and thyroid hormone levels are interfering the functions of normal female fertility. The inspiration for this study to know the present infertility cases (female) by analyzing the following biochemical parameters by estimating the levels of these parameters we can assess the infertility rate in women.

The following biochemical parameters were done. 1.Luteinizing Hormone or Lutropin (LH), 2.Follicular stimulating hormone or follitropin (FSH), 3.Triodothyronine (T3) \& Tetraiodothyronine (T4) or Thryroxin , 4.Thyroid stimulating hormone (TSH)

\section{Results}

Female reproductive hormones measurement are of Diagnostic and therapeutic value in ascertaining the homeostasis of fertility regulation via the hypothalamic-pituitary-gonadal axis. ${ }^{9}$

In our present study thirty normal people were chosen and found that the FSH levels were in the range of 3.9-11.2 IU/L with a mean value of 4.54 and with S.D. of \pm 0.59 and LH levels were in the range of $2.2-9.9$ IU/L with a mean value of 4.58 and with S.D. of \pm 1.38 .

Hypogonadotropic anovulation is caused hypothalamic or pituitary failure. After excluding space occupying lesions in hypothalamic - pituitary regions ovulation can be induced by pulsatile GnRH or recombinant FSH and LH therapy in majority of cases ${ }^{[8]}$.

In our present study cases categorized under normogonadotropic anovulation have significant low levels of gonadotropins compared to controls. Though the values are within normal limits they are not sufficient to initiate normal ovulatory cycle or due to disturbances in hypothalmic - pituitary-ovarian axis.

33 cases of ovulatory dysfunction were chosen for the present study of evaluation of FSH and LH and thyroid hormones levels after elimination of systemic illness, pregnancy,PCOD. In our present study hypogonadotropic anovulation (Group I) was observed in 23 cases (about 10\%) with FSH levels in the range of $0.2-0.9 \mathrm{ng} / \mathrm{ml}$ with a mean value of 1.59 and with S.D. of \pm 0.41 and $\mathrm{LH}$ levels in the range of $0.8-1.2 \mu \mathrm{IU} / \mathrm{ml}$ with a mean value of 0.95 and with S.D. of \pm 0.19 . T3 levels in the range 0.2 to $0.9 \mu \mathrm{IU} / \mathrm{ml}$ with a mean value of 0.53 and with SD of \pm 0.23 and T4 level in the range of 2.6 to $5.4 \mu \mathrm{IU} / \mathrm{ml}$ with a mean value of 4.03 and with SD of \pm 0.81 and TSH level in the range 6.8 to $11.8 \mu \mathrm{IU} / \mathrm{ml}$ with a mean value of 9.03 and with SD of \pm 1.76

Normogonadotropic anovulation groups was observed in 30 cases (about 75\%) with FSH levels in the range of 3.1-5.6 $\mu \mathrm{IU} / \mathrm{ml}$ with a mean value of 4.54 and with S.D of \pm 0.59 and LH levels in the range of 2.1-8.1 $\mu \mathrm{IU} / \mathrm{ml}$ with a mean value of 4.58 and with S.D. of \pm 1.38 . Normo gonado tropic ovulation and normal levels of thyroid function was observed in 30 cases with T3 level in the range of 0.5 to $2.0 \mu \mathrm{IU} / \mathrm{ml}$ with a mean value of 1.40 and with S.D. of \pm 0.71 and T4 levels in the range of 5.5 to $12 \mu \mathrm{IU} / \mathrm{ml}$ with mean value of 8.73 and with a S.D. of \pm 1.98 and TSH level in the range of 1.2 to $5.5 \mu \mathrm{IU} / \mathrm{ml}$ with a mean value of 2.99 and with S.D. $\pm 1.22^{11}$ Hypergonadotropic anovulation groups observed in 10 cases with FSH levels in the range of 42.6-61.4 $\mu \mathrm{IU} / \mathrm{ml}$ with a mean value of 49.19 and with S.D. of \pm 6.76 and LH Levels in the range of 25.9 to $34.1 \mu \mathrm{IU} / \mathrm{ml}$ with a mean value of 6.76 and with S.D. of \pm 2.94 . T3 levels in the range of 3.3 to $5.1 \mu \mathrm{IU} / \mathrm{ml}$ with a mean value3.95 and with S.D. of \pm 0.73 and T4 level in the range of 13 to $16 \mu \mathrm{IU} / \mathrm{ml}$ with a mean value of 14.01 and with S.D. of \pm 0.84 and TSH level in the range 0.26 to $0.5 \mu \mathrm{IU} / \mathrm{ml}$ and with a mean value of 0.34 with SD of \pm 0.07 Observations were depicted in table $1,2,3$. Results were statistically evaluated using student ' $t$ ' test

Table 1 Different Bio-chemical parameters of cases (total cases : 33)

\begin{tabular}{|c|c|c|c|c|c|}
\hline S.No. & $\begin{array}{c}\text { T3 } \\
(\mathbf{m I U} / \mathbf{m l})\end{array}$ & $\mathbf{T 4}(\mathbf{m I U} / \mathbf{m l})$ & $\begin{array}{c}\text { TSH } \\
(\mu \mathbf{1 U} / \mathbf{m l})\end{array}$ & FSH $(\mu \mathbf{I U} / \mathbf{m l})$ & LH $(\mu \mathbf{I U} / \mathbf{m l})$ \\
\hline 1. & 0.8 & 4.8 & 7.0 & 2.1 & 1.1 \\
\hline 2. & 0.6 & 3.8 & 6.8 & 1.6 & 0.9 \\
\hline 3. & 0.3 & 5.1 & 7.1 & 1.4 & 1.2 \\
\hline 4. & 0.6 & 3.9 & 7.3 & 1.5 & 0.8 \\
\hline 5. & 0.7 & 4.1 & 6.9 & 1.7 & 1.2 \\
\hline 6. & 0.12 & 5.3 & 6.8 & 1.3 & 1.3 \\
\hline 7. & 0.21 & 4.9 & 7.3 & 1.7 & 1.2 \\
\hline 8. & 0.5 & 2.7 & 8.1 & 1.6 & 1.1 \\
\hline 9. & 0.3 & 3.6 & 10.2 & 2.1 & 1.0 \\
\hline 10. & 0.6 & 4.2 & 11.3 & 1.6 & 0.7 \\
\hline 11. & 0.2 & 3.8 & 11.2 & 1.3 & 1.2 \\
\hline 12. & 0.5 & 2.6 & 10.8 & 2.0 & 0.7 \\
\hline 13. & 0.8 & 4.3 & 8.3 & 2.1 & 0.9 \\
\hline 14. & 0.7 & 5.2 & 11.2 & 1.7 & 0.8 \\
\hline 15. & 0.9 & 4.1 & 10.3 & 1.3 & 1.0 \\
\hline 16. & 0.7 & 3.9 & 11.8 & 2.0 & 1.2 \\
\hline
\end{tabular}




\begin{tabular}{|c|c|c|c|c|c|}
\hline 17. & 0.3 & 2.9 & 11.2 & 1.7 & 1.0 \\
\hline 18. & 0.8 & 3.2 & 10.1 & 1.3 & 0.7 \\
\hline 19. & 0.7 & 4.3 & 8.3 & 1.4 & 0.9 \\
\hline 20. & 0.2 & 4.8 & 7.4 & 1.4 & 0.8 \\
\hline 21. & 0.7 & 2.7 & 10.2 & 1.3 & 0.7 \\
\hline 22. & 0.4 & 4.7 & 8.9 & 1.2 & 0.8 \\
\hline 23. & 0.6 & 3.9 & 9.3 & 1.4 & 0.8 \\
\hline 24. & 3.5 & 14.1 & 0.31 & 43.2 & 28.6 \\
\hline 25. & 4.8 & 13.8 & 0.42 & 48.3 & 26.8 \\
\hline 26. & 3.6 & 13.1 & 0.32 & 58.9 & 34.1 \\
\hline 27. & 5.1 & 14.7 & 0.26 & 52.9 & 32.2 \\
\hline 28. & 4.7 & 15.8 & 0.31 & 42.6 & 25.9 \\
\hline 29. & 3.8 & 13.6 & 0.41 & 46.5 & 27.4 \\
\hline 30. & 2.8 & 13.3 & 0.36 & 58.9 & 34.1 \\
\hline 31. & 3.3 & 14.7 & 0.5 & 43.2 & 28.4 \\
\hline 32. & 4.2 & 13.8 & 0.28 & 44.5 & 29.8 \\
\hline 33. & 3.7 & 13.2 & 0.26 & 47.9 & 31.2 \\
\hline Mean & $\mathbf{1 . 5 6}$ & $\mathbf{7 . 0 5}$ & $\mathbf{6 . 4 0}$ & $\mathbf{1 5 . 8 6}$ & $\mathbf{9 . 7 1}$ \\
\hline SD & $\mathbf{\pm 1 . 6 5}$ & $\mathbf{\pm 4 . 7 2}$ & $\mathbf{\pm 4 . 3 1}$ & $\mathbf{\pm 2 2 . 2 2}$ & $\mathbf{\pm 1 3 . 5 7}$ \\
\hline
\end{tabular}

Table-2 Different Bio-chemical parameters in controls (total controls $\mathbf{n}=30$ )

\begin{tabular}{|c|c|c|c|c|c|}
\hline S.No. & $\mathrm{T3}(\mathrm{mIU} / \mathrm{ml})$ & $\mathrm{T} 4(\mathrm{mIU} / \mathrm{ml})$ & $\mathrm{TSH}(\mu 1 \mathrm{U} / \mathrm{ml})$ & FSH $(\mu \mathrm{IU} / \mathrm{ml})$ & $\mathrm{LH}(\mu \mathrm{IU} / \mathrm{ml})$ \\
\hline 1. & 1.8 & 5.5 & 1.5 & 4.5 & 2.9 \\
\hline 2. & 1.5 & 5.7 & 1.3 & 4.4 & 4.9 \\
\hline 3. & 1.3 & 8.6 & 4.0 & 5.2 & 7.8 \\
\hline 4. & 1.0 & 7.3 & 3.6 & 4.3 & 2.8 \\
\hline 5. & 0.9 & 5.8 & 5.1 & 5.0 & 3.4 \\
\hline 6. & 1.4 & 10.1 & 4.2 & 4.6 & 5.1 \\
\hline 7. & 1.7 & 11.2 & 3.6 & 4.9 & 5.1 \\
\hline 8. & 1.75 & 8.6 & 2.9 & 5.2 & 5.0 \\
\hline 9. & 1.2 & 7.9 & 1.3 & 5.5 & 3.4 \\
\hline 10. & 1.1 & 11.3 & 0.9 & 4.4 & 5.1 \\
\hline 11. & 1.4 & 6.8 & 1.3 & 4.7 & 3.2 \\
\hline 12. & 1.3 & 11.4 & 4.2 & 4.6 & 4.8 \\
\hline 13. & 0.9 & 9.6 & 3.1 & 4.4 & 5.2 \\
\hline 14. & 1.6 & 8.9 & 4.3 & 4.8 & 4.9 \\
\hline 15. & 1.25 & 6.7 & 2.8 & 3.2 & 2.1 \\
\hline 16. & 1.6 & 8.1 & 4.3 & 4.1 & 5.0 \\
\hline 17. & 1.9 & 11.2 & 2.2 & 4.4 & 5.3 \\
\hline 18. & 0.8 & 8.3 & 1.9 & 3.5 & 2.8 \\
\hline 19. & 1.1 & 7.8 & 4.6 & 4.9 & 4.5 \\
\hline 20. & 1.3 & 6.1 & 3.2 & 4.8 & 3.6 \\
\hline 21. & 1.4 & 8.4 & 5.0 & 4.6 & 3.9 \\
\hline 22. & 1.0 & 5.6 & 4.6 & 3.8 & 2.7 \\
\hline 23. & 0.9 & 10.1 & 3.3 & 4.2 & 4.9 \\
\hline 24. & 4.8 & 12.2 & 2.8 & 5.2 & 7.6 \\
\hline 25. & 1.2 & 10.8 & 1.9 & 4.4 & 6.4 \\
\hline 26. & 1.6 & 11.1 & 2.4 & 5.1 & 5.6 \\
\hline 27. & 1.0 & 8.9 & 1.8 & 4.4 & 6.2 \\
\hline 28. & 0.9 & 10.2 & 1.9 & 5.6 & 4.8 \\
\hline 29. & 1.1 & 9.8 & 3.2 & 4.4 & 5.1 \\
\hline 30. & 1.40 & 7.9 & 2.6 & 3.2 & 3.4 \\
\hline Mean & 1.40 & 8.73 & 2.99 & 4.54 & 4.58 \\
\hline S.D. & \pm 0.70 & \pm 1.97 & \pm 1.22 & \pm 0.59 & \pm 1.38 \\
\hline
\end{tabular}

Table 3 Mean and SD values of various bio-chemical parameters in controls and total cases (Hypo+Hyper)

\begin{tabular}{|c|c|c|c|c|c|}
\hline \multirow{2}{*}{ S.No. } & \multirow{2}{*}{ Parameter } & \multicolumn{2}{|c|}{ Mean \& SD } & \multirow{2}{*}{ P value } & \multirow{2}{*}{ Remarks } \\
\cline { 3 - 4 } & & Control (30) & Cases (33) & & \\
\hline 1. & T3 & $1.40 \pm 0.71$ & $1.56 \pm 0.96$ & $<0.001$ & Significant \\
\hline 2. & T4 & $8.73 \pm 1.98$ & $7.21 \pm 1.65$ & $<0.001$ & Significant \\
\hline 3. & TSH & $2.99 \pm 1.22$ & $6.40 \pm 1.83$ & $<0.001$ & Significant \\
\hline 4. & FSH & $4.54 \pm 0.59$ & $16.0 \pm 7.17$ & $<0.001$ & Significant \\
\hline 5. & LH & $4.58 \pm 1.38$ & $9.71 \pm 3.13$ & $<0.001$ & Significant \\
\hline
\end{tabular}




\section{Discussion}

The dysfunctioning of the Lutropin (LH), ${ }^{[14]}$ follicular stimulating hormone (FSH) and thyroid hormone levels, estrogen levels, progesterone levels and serum prolactin levels are interfering the functions of normal female fertility

The inspiration for this study to know the present infertility cases (female) by analyzing the following biochemical parameters. By estimating the levels of these parameters we can assess the infertility rate in women.

Hypergonadotropic anovulation indicates premature ovarian failure and early menopause. Fertility can not be restored in these cases. These cases should be followed up for autoimmune disorders. Measurement of FSH and LH differentiates between ovarian and hypothalamic - pituitary causes of hypoestrogenism.

T3 Hormone levels -The mean T3 level in the study group was $1.56 \pm 0.96$. The difference between mean of the two groups statistically significant and we also compare the mean of Hypohormonal cases i.e. 0.53 \pm 0.23 and in hyperhormonal cases i.e. 3.95 \pm 0.73 . It is also shows significant levels.

T4 Hormone levels-The mean T4 level in the study group was $8.73 \pm 1.98$. The difference between mean of the two groups statistically significant and we also compare the mean of Hypohormonal cases i.e. 4.03 \pm 0.81 and in hyperhormonal cases i.e. $14.01 \pm 0.84$. It is also shows significant levels. $\left.{ }^{[11} 12\right]$

TSH Hormone levels -The mean TSH hormone level in the study group was $2.99 \pm 1.22$. The difference between mean of the two groups statistically significant and we also compare the mean of Hypohormonal cases i.e. $9.02 \pm 1.76$ and in hyperhormonal cases i.e. $0.34 \pm 0.07$. It is also shows significant levels ${ }^{[13]}$

FSH Hormone levels -The mean FSH hormone level in the study group was $4.54 \pm 0.59$. The difference between mean of the two groups statistically significant and we also compare the mean of Hypohormonal cases i.e. $1.59 \pm 0.41$ and in hyperhormonal cases i.e. $49.19 \pm 6.76$. It is also shows significant levels. ${ }^{[13]}$

LH Hormone levels -The mean LH hormone level in the study group was $4.58 \pm 1.38$. the difference between mean of the two groups statistically significant and we also compare the mean of Hypohormonal cases i.e. $0.95 \pm 0.19$ and in hyperhormonal cases i.e. 29 . $8 \pm 2.94$. It is also shows significant levels.

\section{Summary \& Conclusions}

Evaluation of Follicle Stimulating Hormone (FSH) and Luteinizing Hormone (LH) and thyroid hormone levels, in cases of female infertility due to ovulatory dysfunction is extremely useful in determination of the diagnosis. FSH and LH thyroid hormone levels are useful in selection of treatment plan and can also assess the outcome of the treatment. In our present study variations of FSH and LH thyroid hormone levels, in patients suffering from ovulatory dysfunction were significant to classify the patients into three district functional groups.

Further evaluation of normogonadotropic anovulation revealed that functional hypothalamic - pituitary dysfunction is a major cause of ovulatory dysfunction. We tried to assess by our study the some endocrinal hormonal levels in infertility cases of women. We have done the comparative study of all parameters with control subjects and cases of both hypo and hyper hormone levels. We have also compared the level of all parameters between the hypo and hyper gonadotrophic anovulation.

\section{References}

[1]. Allan G. Gornal, Allan W.Luxton, Bhagu R. Bhavnani: Endocrine disorders. Applied Biochemistry of clinical Disorders, $2^{\text {nd }}$ edition, 285-296.

[2]. Ann M. Gronowski; Mary Landau - Levine: Reproductive Endocrine Function, Tietz Textbook of clinical Chemistry, $3^{\text {rd }}$ edition. 1606- 1626.

[3]. Ervin E. Jones, Stephen P. Boyers: Ovarian evaluation - Amenorrhea. Decision making in Infertility, 1st editil on 12- 21

[4]. Babek Imani et al: Ovulation induction in normogonadotropic infertility. Journal of clinical Endocrinology and Metabolism, Vol.83, No.7, 2361-2365.

[5]. Curcl:1od A. et al : Value and Limitations of FSH and LH assay in female sterility and amenorrhea. Schweiz Med Wochenschr, 31; 101 (30) : $1114-21$

[6]. Davajan V, K letzky OA: Amenorrhea. Infertility contraception and Reproductive Endocrinology 3rd edition p373.

[7]. Ervin E. Jones, Stephen P. Boyers: Ovarian evaluation - Amenorrhea. Decision making in Infertility, 1st edition 12- 21.

[8]. Visser A.J. et al: Normogonadotropic anovulation. The journal of clinical Endocrinology and Metabolism, 89(1): 318 - 323.

[9]. Stephen P. Boyers Ervin S.Jones: Ovulatory function evaluation. Decision making in infertility, 1st edition 10-11.

[10]. WHO : WHO scientific group on classification of anovubtion.

[11]. P. Reed Larsen et al; Thyroid gland; William's textbook of endocrinology; P.No.418. .

[12]. J.D.Nath et al; Serum T4, T3 Level in infertile women; Ind. Jour; vol-40; 407-9.

[13]. Bruce R. Carr: Disorders of the ovaries and Female Reproductive Tract. Williams Textbook of Endocrinology, 9th edition, 751 817.

[14]. Rajan R: Reproductive Hormones. Postgraduate reproductive Endocrinology, 3rd edition. 11-33. 